\title{
Minha mãe pintou meu pai de branco: afetos e negação da raça em famílias interraciais
}

\author{
My mother painted my father in white: affections and denial of race in \\ interracial families
}

http://dx.doi.org/10.5007/2178-4582.2017v51n2p439

\author{
Lia Vainer Schucman, Belinda Mandelbaum e Felipe Luis Fachim \\ Universidade de São Paulo, São Paulo/SP, Brasil
}

\begin{abstract}
Este artigo, parte de uma pesquisa maior sobre famílias inter-raciais, tem como propósito descrever as formas pelas quais o negro, a história negra e a ancestralidade negra têm sido negadas no discurso das famílias inter-raciais. Para esta compreensão, apresentaremos o estudo de caso de duas famílias. Os resultados obtidos na pesquisa maior nos mostraram que a família é um espaço privilegiado para o desenvolvimento de estratégias de enfrentamento da violência racista vivida na sociedade de forma mais ampla, mas também o locus de legitimação e vivência racistas. E dentro destas vivências foi possível perceber que um dos mecanismos psíquicos usados para negociar os conflitos e tensões raciais de nossa sociedade no interior das famílias é a negação do Outro como negro.
\end{abstract}

Palavras-chaves: Racismo. Negação. Famílias Interraciais. Raça, Branquitude.
This article, a piece of a bigger research about interracial families, aims to describe the ways in which black, black history and black ancestry have been denied in the discourse of interracial families. For this understanding we present the case study of two families with the intention of thinking about the place of the race in these dynamics. The results obtained in the bigger research pointed out that family is a privileged institution for the development of strategies against racial violence expriencied in society on a larger scale, but also the place where it is possible to legitimate racist experiences and race violence. And, within these experiences, it was possible to realize that the psychosocial mechanism of denial is one of several ways of negotiating the conflicts and racial tensions that are enunciated within these families.

Keywords: Racism. Denial. Interracial Families. Race. Whiteness.

\section{INTRODUÇÃO}

Este artigo tem como objetivo central descrever, através do estudo de caso de duas famílias inter-raciais, as formas pelas quais o negro, a história negra e a ancestralidade negra têm sido negadas no interior das dinâmicas de famílias inter-raciais. O impulso para esta análise se deu a partir dos resultados de outra pesquisa, mais ampla, desenvolvida por nós. Esta pesquisa teve como objetivo investigar e compor uma análise de como famílias interraciais vivenciam, negociam, legitimam, constroem e desconstroem os significados da raça e, particularmente, do racismo cotidiano vivenciado pelos membros não brancos destas famílias.

Os resultados desta pesquisa mais ampla mostraram que existem diferentes formas individuais e coletivas de responder às hierarquias raciais 
que estruturam a sociedade brasileira. Essa diversidade no interior das famílias mostra que ali é um dos espaços privilegiados para o desenvolvimento de estratégias para o enfrentamento, acolhimento e elaboração da violência racista vivida na sociedade de forma mais ampla, mas também aponta o lugar de legitimação das hierarquias raciais da estrutura social na qual estas famílias estão inseridas. Para este artigo em especial, escolhemos observar um mecanismo que nos pareceu bastante recorrente e importante para se pensar as formas pelas quais membros destas famílias legitimam o racismo estrutural de nossa sociedade: o mecanismo de negação do negro.

A discussão sobre raça e racismo no campo das Ciências Sociais e Humanas tem sido tematizada por intelectuais e pesquisadores brasileiros e estrangeiros desde a criação das primeiras universidades no Brasil. Contudo, são raros os estudos que relacionam dinâmicas familiares e relações raciais, bem como incipientes os trabalhos que falam de vínculos afetivos e a relação com os processos de racialização no país.

No Brasil, o estudo de Barros (2003) traz à tona a necessidade de um novo modelo de análise das famílias inter-raciais que esteja de acordo com a contemporaneidade, uma vez que a bibliografia sobre o tema tem sido mais calcada em dados demográficos. Poucos trabalhos analisam qualitativamente o tema. Outra constatação que tivemos ao analisar as pesquisas que enfocam casamentos e famílias inter-raciais no Brasil é o fato de que a maioria destas pesquisas problematiza suas análises apenas no sujeito negro e, muitas vezes, limita-se a fazer associações mecânicas por meio das quais o casamento inter-racial é visto como estratégia de ascensão social e embranquecimento, contribuindo para que os brancos e as brancas que escolhem esta maneira de se relacionarem também não sejam mencionados em tais análises. É exatamente para lidar com esta lacuna na literatura que este artigo foi pensado. Nós trabalharemos aqui com o intuito de apontar uma das dinâmicas possíveis pelas quais os membros brancos de relações familiares inter-raciais negociam os conflitos e tensões raciais dentro destas relações.

Este entrecruzamento de perspectivas evidencia que a raça e o racismo são uma questão importante de se pensar dentro das relações familiares. A discussão e o aprofundamento dos assuntos referentes aos modos como as famílias inter-raciais vêm lidando com as questões raciais podem contribuir para a elaboração de referenciais teóricos que nos apontem caminhos alternativos ao sofrimento psíquico causado pelo racismo em membros de famílias inter-raciais. 


\section{A PESQUISA}

Para a realização desta pesquisa, foram feitas entrevistas ${ }^{1}$ com famílias inter-raciais, por meio das quais foi possível compreender como os sujeitos se apropriam do significado de raça e como se apropriam de diversos discursos sobre o tema. Escolhemos, aqui, duas famílias para construir uma narrativa e sua respectiva contextualização técnica. A escolha de cada uma delas está relacionada com o tema específico deste artigo, a dinâmica da negação. É importante ressaltar que a dinâmica da negação é apenas uma das diversas formas com que os sujeitos lidam com as tensões raciais de nossa sociedade, não sendo possível generalizar. Contudo, sua formulação é importante para a compreensão de um dos efeitos psicossociais do racismo brasileiro. Nesse sentido, traçamos assim nossas entrevistas: um roteiro de entrevista delimitou focos norteadores sobre as relações inter-raciais e a relação de cada sujeito com as categorias raça e racismo. As perguntas foram construídas com o intuito de perceber se e como os sujeitos destas famílias legitimam e/ou desconstroem as hierarquias raciais dentro de suas relações íntimas familiares. Nestas perguntas estavam incluídas as formas de autoclassificações raciais de cada integrante familiar, se eles acreditavam ter vivido racismo dentro da família, como cada um interpretava os códigos raciais de nossa sociedade, entre outros.

É importante reconhecer, neste trabalho, que a entrevista é um componente fundamental, irradiador de formulações e, ao mesmo tempo, sua comprovação. Ela é tratada com extremo rigor, atenção e respeito, uma vez que, em alguns momentos, pode transparecer que o pesquisador atravessou algum limite interpessoal. Ressaltamos e ponderamos: se houver, a impressão é apenas uma impressão. Todos os entrevistados foram consultados antes de terem suas falas aqui expostas, além da óbvia proteção que o anonimato lhes dá. Há nas entrelinhas dos fragmentos transcritos uma construção de confiança que permitiu a ambos, pesquisadores e pesquisados, uma interação franca, direta e com níveis de tensão característicos do tema. Não podemos esquecer que este é um dos temas tabu em nossa sociedade, um tema que exige e enseja cuidados e, acima de tudo, muita transparência. A decisão, portanto, e com todo o rigor possível, de conduzir mais uma conversa franca do que uma entrevista protocolar e técnica. A pesquisa cumpre os princípios éticos em vigência no país bem como os contidos na Declaração de Helsinki e todos os participantes assinaram termo de consentimento livre e esclarecido.

1 A Familia Alves foi entrevistada por Lia Vainer Schucman e Felipe Fachin, e a Família a Gomes por Lia Vainer Schucman. A divulgação dos nomes dos membros das famílias não foi autorizada, portanto são ficticios. As entrevistas foram realizadas em São Paulo, local de residência das famílias e tiveram duração aproximada de cerca de 3 horas de duração cada. 
Relatamos, agora, algumas características institucionais que determinaram parte da realização deste trabalho. Fui (a primeira autora deste artigo), no momento da pesquisa, uma pesquisadora vinculada como pós-doutoranda em um Instituto de Psicologia de uma universidade do estado de São Paulo, mais especificamente no departamento de psicologia social. Dentro deste departamento, estou inserida em um laboratório de estudos da família, de relações de gênero e sexualidade. No compartilhamento de algumas das atividades desenvolvidas neste laboratório, tive a parceria de um bolsista de iniciação cientifica. Este participou das duas entrevistas aqui arroladas e também da construção da análise dos dados. Deste modo, as entrevistas aconteceram com dois entrevistadores. Vale dizer que o fato de eu estar inserida dentro das discussões acadêmicas e não acadêmicas sobre a temática racial brasileira possibilitou que eu tivesse contato com diversas pessoas e famílias inter-raciais dentro mesmo de meu circuito social e profissional. A localização destas famílias, portanto, não ofereceu maiores desafios para a construção inicial desta pesquisa.

\section{AS FAMÍLIAS}

A primeira pergunta que nós fizemos após elaborar a ideia da pesquisa foi a de como poderíamos considerar que uma família é inter-racial. Ou seja: quais apontamentos preliminares são possíveis de se fazer, sobre qual família e como ela pode ser considerada inter-racial? O primeiro apontamento é contextualizar o conceito de raça aqui considerado. Partimos do pressuposto de que raça é uma construção social que produz sentidos no cotidiano das pessoas e que engendra e mantém profundas desigualdades materiais e simbólicas nas vidas dos brasileiros (BENTO, 2007; CARONE, 2007; HASENBALG, 1979; SCHUCMAN, 2012). Assim, o conceito de raça usado para nortear a pesquisa é o de "raça social" que, conforme Guimarães (1999, p. 153), não se refere a um dado biológico, mas a "construtos sociais, formas de identidade baseadas numa ideia biológica errônea, mas eficaz socialmente para construir, manter e reproduzir diferenças e privilégios". Para esse autor, se a existência de raças humanas não encontra qualquer comprovação no bojo das ciências biológicas, elas são, contudo, "plenamente existentes no mundo social, produtos de formas de classificar e de identificar que orientam as ações dos seres humanos" (GUIMARÃES, 1999, p. 153).

É importante salientar também o modo como estamos pensando a “família”. Mandelbaum (2008, p. 1) aponta "a relevância de pensar a família como instituição social, historicamente determinada. As transformações econômicas, sociais e culturais sempre impactaram a família, produzindo 
mudanças em seus arranjos, em suas dinâmicas e suas relações com o mundo". E sugere ainda que é preciso compreender:

\begin{abstract}
a família como campo de interseção entre a realidade social e a vida psíquica, uma tessitura que, em seu arranjo de parentesco e nos significados que atribui a cada um dos lugares que a compõem, sofre a determinação de uma história sociocultural na qual se estabelece e que a atravessa, ao mesmo tempo em que é constituída na interação afetiva entre os membros. Toda família constitui um microcosmo fincado nas intermediações entre a esfera social e individual, o público e o privado, o real e a representação, o biológico e o cultural (MANDELBAUM, 2008, p. 19).
\end{abstract}

Posto isto, e sabendo que raça é uma construção social e que a família é uma instituição que se constrói no tecido social na qual está inserida, é preciso pensar que as classificações raciais também são construções. Como já constatado na literatura antropológica, as classificações raciais são relacionais e situacionais (HASENBALG, 1979; MOUTINHO, 2004; SANSONE, 1993): uma mesma família pode ser considerada inter-racial em um momento e em outro, não, dependendo da interlocução e de critérios outros. Um exemplo disto foi a família Alves, que é composta por: Valéria, seus filhos João e Maria e a neta Joana. Nesta família, como veremos, as classificações raciais se modificam dependendo de quem responde a questão. Portanto, se nossa primeira informante fosse Valéria, estaríamos diante de uma família - considerada por ela - branca. Mas nosso primeiro contato com a família foi através de João. Ele a considera uma família inter-racial, já que se autoclassifica como negro.

Diante deste impasse, decidimos, dentro de um quadro rigoroso de aferição, que as famílias escolhidas deveriam ser consideradas inter-raciais pelos entrevistadores e também por algum membro da família. A escolha de duas famílias para análise se deve ao fato de que o conjunto global das entrevistas gerou um material muito extenso e denso. Portanto, era preciso limitar. Mas também existe o fato de muitos modelos internos de discursos raciais se repetirem. Isso fez com que selecionássemos as interações mais eloquentes e significativas sobre o tema da negação, precisamente, as duas famílias supracitadas.

\title{
A FAMÍLIA ALVES
}

A família Alves é composta por Valéria, 50 anos, nascida na Bahia e residente em São Paulo durante a maior parte de sua vida. Valéria recentemente completou o ensino básico, por meio de um supletivo e trabalha como dona 
de casa. Tem dois filhos (João e Maria). Valéria se autoclassifica racialmente como branca. João, 27 anos, graduado por uma universidade pública do estado de São Paulo, trabalha como professor em uma escola municipal de ensino fundamental. João se reconhece como homossexual e preto. Maria, 35 anos, tem ensino médio completo e trabalha no mercado da beleza como cabeleireira e manicure. É mãe de Joana, fruto de um relacionamento da juventude que não prosseguiu. É casada e se autoclassifica como branca. Joana, 16 anos, cursava o segundo ano do ensino médio em uma escola estadual na região. Registrada como parda, ela se autoclassifica como mulata. A família é residente do bairro do Limão, sendo que Maria morava com o marido e a filha em outra casa. João morava com Valéria. Na entrevista, todos estavam presentes na casa de Valéria e todos se autoclassificaram como pobres.

\section{A FAMÍLIA GOMES}

A Família Gomes é composta pela mãe Estela, 66 anos. Ela trabalha como dona de casa e se autoclassifica como branca de origem Italiana. O pai Walmor, 74 anos, fez ensino técnico e trabalhou de operário em uma fábrica de carros em São Bernardo do Campo, cidade onde residem. Walmor se autoclassifica como preto e diz não saber sua origem. As duas filhas Priscila, 40 anos, e Juliana, 36 anos, autoclassificam-se como pardas, em situações que elas nomeiam como "técnicas" e negras, quando a pergunta é - nas palavras delas - do "dia-a-dia". A entrevista foi feita no apartamento onde hoje moram Estela e Walmor. Estavam presentes apenas Juliana e Estela. Ambas se declararam pertencentes à classe-média, afirmando terem carro, casa própria e curso superior (no caso das filhas).

\section{FAMÍLIAS ALVES E GOMES: A NEGAÇÃO DO NEGRO}

Tal como a investigação de Barros (2003), nossa pesquisa mostrou a diversidade de formas com que cada família, e particularmente cada membro delas, lida com a questão racial e o racismo de nossa estrutura social. A primeira singularidade do nosso trabalho, no entanto, foi a forma como Valéria, a mãe da família Alves, apresentou-nos os membros negros da família, negando neles qualquer possibilidade de se reconhecerem como negros e negando também para si este fato (chegamos a esta família através de João, amigo de um dos pesquisadores e, já na casa, fomos recebidos por Valéria). A gama de classificação de cores foi confusa durante toda a entrevista e os primeiros dez minutos foram de completo desentendimento quanto às classificações raciais. Nós (os pesquisadores) fizemos uma heteroclassificação de cor/raça bastante diferente da dos próprios entrevistados. A nosso ver, aquela era uma família, com exceção de Maria, composta por negros. Na classificação de Valéria, era 
uma família de não negros. Isso demonstra o que Guimarães (2003) e Moutinho (2004) já haviam apresentado em suas pesquisas: sempre pode haver diferenças entre as categorias nativas e as dos pesquisadores (GUIMARÃES, 2003). É importante ressaltar que a própria família tem discordâncias internas marcadas por posições ideológicas e condições sociais distintas. Nós, pesquisadores, além de toda a literatura que permeia o assunto, temos o olhar marcado pela forma regional paulistana e pela geração influenciada no modelo branco/ negro. Como aponta D'Adesky (2001, p. 135), esse modelo tem sido os mais usados pelas organizações, movimentos negros e pesquisadores das ciências sociais. D’Adesky (2001, p. 135) indica o uso de cinco modos de classificação racial: 1) o uso das cinco categorias oficiais do IBGE; 2) "o sistema branco, negro e índio, referente ao mito fundador da civilização brasileira"; 3 ) o sistema classificatório popular de 135 cores, segundo apurado pela Pesquisa Nacional por Amostra de Domicílios (PETRUCCELLI; SABOIA, 2013); 4) o modo binário branco e não-branco usado por inúmeros pesquisadores nas Ciências Humanas e 5) o modelo binário branco e negro, proposto pelas organizações e movimentos negros.

Apesar de todas estas diferenças marcadas pelas posições dos sujeitos no mundo, a mãe na família Alves parece ter a palavra de legitimação e poder sobre os outros membros, pois, na dinâmica de perguntas e respostas, foi perceptível que, mesmo quando dirigida a outros membros, a pergunta era respondida primeiramente pela mãe. Recortamos um pedaço da entrevista para demonstrar essa complexidade em relação à classificação racial da família:

Pesquisadores: No censo, como você responde sobre sua classificação racial?

João: no meu registro é pardo e, em grande parte da minha vida, eu respondi como pardo. Minha mãe me chama de moreno claro, não me reconhece como negro. Hoje eu respondo como negro, e a questão de eu responder como negro é bem recente.

Pesquisadores: Como foi isso para você? De passar dessa resposta de pardo para negro?

João: É porque pardo, para mim, é uma coisa meio estranha, assim. E acho que negro, de repente, traduz melhor a minha origem. Até culturalmente. Sempre tive a cultura negra por perto. Samba, não sei o quê. A dança. Sempre fui mais próximo da cultura negra do que da cultura branca, digamos assim. Eu acho que faz mais sentido me identificar, porque pardo eu acho 
meio estranho. E negro aqui na zona norte está ligado à tradição das escolas, do samba, da música, tudo que eu me identifico.

$\mathrm{Na}$ fala acima, podemos perceber que a mãe classifica o filho segundo a cor (moreno claro) e o filho, ao se autoclassificar como negro por meio de identificações com a cultura negra e sua origem, remete à categoria sociológica de raça, que tem sido a opção mais comum para os sujeitos universitários inseridos dentro dos movimentos sociais negros. Logo após a resposta dada pelo filho, a mãe olhou para nós e disse: "Ele começou com isto depois de ir para a universidade, mas ele não é negro". Temos aqui uma primeira negação: a opção de classificação do filho é negada pela mãe. É interessante pensarmos no conceito de negação formulado por Freud (1976) em 1925. Ali, o conceito aparece como um mecanismo que se dá no nível da linguagem e que não impede a operação do recalque. Na negação, o recalque continua operando e o que vem à tona na fala do sujeito é a representação recalcada que só será manifesta na condição de um "não" em sua frase formulada. Através da formulação "mas ele não é negro" é possível, interpretar o referido enunciado nos termos de Freud (1925 [1976], p. 1): "Ao interpretar, tomamos a liberdade de deixar de lado a negação e escolher o conteúdo puro da ideia”. Assim, é como se a mãe tivesse dito: "ele é negro, mas não me é confortável admitir isto".

É possível, com base nesse singelo dado preliminar, ter alguns elementos para compreender uma das grandes confusões nas classificações da mestiçagem brasileira. Ou seja, a mãe, quando diz que o filho é moreno claro, olha apenas a coloração da pele, típica forma de classificar, como aponta Sansone (1993), de sua geração e regionalidade (Bahia). Cor, para a mãe, não tem relação com origem ou cultura, mas é apenas uma característica fenotípica. Ao mesmo tempo, podemos interpretar que a cor é uma forma que ela "arranjou" para fugir dos estereótipos negativos construídos sobre o negro. Mas é preciso atenção: quando ela afirma que "ele não é negro", pode estar se referindo a diferentes coisas. A primeira hipótese, mais comum na sociedade brasileira, é que esta mãe acredita que ser negro é algo ruim e, por isto, o filho dela não é. Esta frase ainda pode ser entendida como "ele não é tão escuro" e, neste sentido, há outras passagens da entrevista que ajudam a perceber por que a mãe não enxerga a família como negra. Quando perguntamos sobre os ancestrais, ninguém soube dizer quem são os negros e de onde vem a origem negra da família:

João: Eu sou louco para saber dos ancestrais. Mas é muito difícil, porque não fica [...] porque, como é muito misturado, não fica muita lembrança. 
Valéria: Minha mãe era de origem italiana. O meu pai, nem sei, porque as irmãs dele eram loiras, loiras, de olhos claros. Só meu pai que era moreno claro assim. Era moreno claro, que nem o meu filho. Era até mais claro, assim.

Os ancestrais lembrados são os brancos. A mãe, baiana, lembra-se de sua origem italiana, mas seu pai, nomeado por ela como moreno claro - e que é onde provavelmente está a origem negra - aparece na fala como algo difuso, distante, cuja origem é desconhecida. Há nesta família, por parte da mãe, uma forte dinâmica de esquecimento e negação do negro:

Pesquisadores: Teu pai é negro? [pergunta feita olhando para João]

Valéria [antes dele]: Não. Ele [pai] não é negro. Ele é moreno. [João não responde].

Pesquisadores: Então, você é o único negro da família? E como é para você isso? Teve uma questão?

João: Ah, quando eu era pequenininho era uma questão. Eu era diferente e eu queria ser igual a todo mundo, né? De qualquer forma, hoje não é uma questão, pois eles não me consideram negro [risos].

Pesquisadores: Tem alguma situação que você lembra, quando era pequeno?

João: Eu lembro vagamente. Lembro-me das histórias da cândida, que eu queria tomar banho de cândida. Lembro de algumas coisas assim, tinha uma questão de eu não querer ser negro. A questão era querer ser parecido com todo mundo da casa. Era mais essa questão, assim, que eu lembro.

Valéria: Era se sentir diferente. Os irmãos todos brancos e só ele moreno.

Maria: A nossa origem é meio estranha, não dá muito para saber. Porquê da família dela [da mãe], por parte do meu avô, 
tem italianos e tal. Da parte da minha avó, não dá para saber muito.

João [respondendo à pergunta anterior]: Do meu pai, sim, também tem negros. Tanto que minha irmã por parte de pai, ela é negra.

Maria: Da parte do meu pai, mas ninguém sabe me confirmar isto, eu tenho desconfiança que tenha alguma ascendência árabe ou alguma coisa assim, porque são muito escuros.

Valéria: O João é o árabe da família, a gente vive chamando ele de terrorista [risos].

Esta parte da entrevista traz diversas passagens para pensarmos o funcionamento pelo qual Valéria nega a presença negra em sua família. $\mathrm{Na}$ primeira pergunta feita para João sobre o pai, ex-marido de Valéria, percebese que, quando ela diz que o pai de João não é negro, ela está negando tanto a negritude do pai quanto a do filho. Contudo, negar que eles são negros não significa dizer que ela os enxerga como brancos. Essa é a complexidade tanto das relações raciais brasileiras quanto do mecanismo de negação. Negar, no sentido estrito da palavra, significa afirmar que uma coisa não existe, que não é verdadeira. Só é possível dizer que Valéria nega algo porque há, em outro lugar e em outros discursos da família e dela mesma, situações que afirmam a existência do componente negro na família. Neste sentido, quando ela mesma afirma que ele - o filho - era diferente de todos os outros da família, ela está dizendo que ele não é branco. Também é possível interpretar que o que ela nega não é a exatamente a cor do outro e sim a memória dessa cor, pois, ao afirmar que a cor de João tem ascendência árabe, ela constrói uma estratégia de aceitação. Neste caso, não se sustenta a origem árabe da família: há em sua genealogia diferentes dados que apontam para uma ascendência de origem negra africana (local de onde vieram os avós; o pai de João é descendente de ex-escravos, etc.). O único dado relatado para "apresentar" a possível origem árabe foi exatamente a cor. Maria, a filha branca, parece pactuar com a mãe quando também afirma uma descendência árabe. A pergunta que podemos fazer, portanto, é: o que, afinal, está sendo negado? E por que se nega?

Negar esta origem pode significar distintas coisas. A primeira, e mais comum. Conforme dito anteriormente, é a tentativa de se distanciar de tudo que representa ser negro em uma sociedade racista como a brasileira. Ao se 
distanciar da representação do negro, o sujeito retira quem ama - filho, marido - do grupo dos negros e mantém a representação negativa do negro intacta. $\mathrm{Ou}$ seja, ao negar a negritude ao "outro" com quem se relaciona, Valéria mantém e legitima os significados negativos construídos em nossa sociedade sobre o negro, sem precisar rever, re-significar e desconstruir o racismo em que foi socializada.

Há outras falas que nos mostram que Valéria e Maria, mesmo tendo se relacionado com negros e com filhos considerados negros, não adquiriram consciência das hierarquias raciais. Ou seja, percebemos que tanto uma como a outra se relacionam com o outro negando-lhe a possibilidade de ser outro. Neste sentido, salta uma das características mais fortes da branquitude, que Bento (2007) apontou como narcísica: a identidade construída em torno de si, em que não há espaço algum para a alteridade. Mesmo onde parece existir um encontro como nas famílias inter-raciais, o outro é apagado: enxerga-se ou projeta-se no outro aquilo que se "é" ou se pretende ser: não negro. João pode ser moreno claro, pode ser árabe, pode tomar banho de cândida, só não pode ser o que ele mesmo diz que é: negro.

\section{OUTRAS FORMAS DE NEGAR}

Impactados com tais achados, fomos procurar em nossas anotações outras falas e formas por meio das quais os membros brancos destas famílias produziriam mecanismos de negação do outro. Na família Gomes, o depoimento de uma das filhas foi marcante, operando a partir de duas formas de negação. A primeira dessas formas mostra, mais uma vez, que o membro branco da família não enxerga o outro como negro. A segunda é a tentativa de aniquilar no outro tudo aquilo que possa lembrar qualquer traço de negritude:

Juliana: Minha família é muito difícil nesse quesito de raça. A família da minha mãe é de italianos, daqui de São Bernardo, e a família do meu pai é negra. Mas parece que minha mãe pintou meu pai de branco [risos], ela nunca sequer falou a palavra "negro" para descrevê-lo. Eu não entendo como, mas ela parece ter continuado racista, aliás, eu sinto ela bem racista. Quando eu era pequena e ia passar fim de semana com minhas primas por parte de pai, eu adorava aquele aconchego que tinha no momento de todas nós trançarmos os cabelos, e mesmo que meu cabelo fosse mais liso que o delas, eu pedia para minha tia trançar; quando eu chegava em casa, minha mãe falava que estava horrível e tirava correndo. Eu não entendia, mas hoje sei que é porque eu ficava mais 'negra'. E hoje isto continua de outra forma, ela não gosta quando eu uso brincos muito grandes ou roupas coloridas, diz que é roupa de negros. 
A fala de Juliana aconteceu em um momento em que a mãe já não estava mais presente na sala. As palavras dela são autoexplicativas. O que marca o depoimento é que ela, como filha, aponta como esta negação do negro por parte da mãe foi violenta para a própria percepção de si e aceitação de seu corpo.

\begin{abstract}
Juliana: Minha mãe falava que eu era quase branca, mas que meu nariz não era de branco, ela falava rindo. Quando eu era pequena, sempre tinha esta sensação de tentar ser algo que não sou, uma sensação de corporalmente inadequada. E, quando eu tive filho, ela disse que se eu passasse bastante a mão no nariz dele enquanto ele era bebê, afinando a forma, o nariz podia melhorar, porque ainda era só cartilagem.
\end{abstract}

Juliana nos mostra que o racismo velado dentro de uma família é caracterizado pela extrema negação do outro, neste caso, do integrante negro. Suas consequências podem ser brutais para o psiquismo de quem nasce e cresce com a ambiguidade de uma mãe que ama seu filho e, ainda assim, violenta-o. É por isto que Juliana diz que se sentia fisicamente inadequada, pois o amor de mãe era também um amor narcísico, que "acha feio o que não é espelho". Neste sentido, Costa (1983, p. 2-3) observa que:

A violência racista do branco é exercida, antes de mais nada, pela impiedosa tendência a destruir a identidade do sujeito negro. Este, através da internalização compulsória e brutal de um ideal de Ego branco, é obrigado a formular para si um projeto identificatório incompatível com as propriedades biológicas do seu corpo.

E é este corpo negro que, para atingir o ideal branco, sofre, querendo tomar banho de cândida, desfazer as tranças e afinar o nariz.

Estela, a mãe de Juliana, assim como Valéria, não negociou sua branquitude ao se relacionar com um negro, pelo contrário: a brancura como ideal de beleza e ideal do humano continuaram seguindo como norma. Com base nisso, podemos formular a pergunta: como pessoas com o racismo tão arraigado tiveram abertura para se relacionar afetivamente e até mesmo amar companheiros, filhos e netos negros? O que nos parece é que, ao se envolverem afetivamente com negros, elas se "cegaram" para a cor deles. As falas acusam em diversos momentos este tipo de mecanismo. É a isto que estamos chamando de negação. Na entrevista com a família Alves, a fala de Valéria sobre a neta Joana parece evidenciar isto ainda mais: 
Pesquisadores: É a cor, a raça, uma questão na família?

Valéria: Não. Acho que não. Acredito que não. Na família, não. Ah, sim! Teve da época da Maria, com o pai da Joana, que era o marido dela. Teve isso da família, que teve aquele racismo. Porque ele era negro, negro, e ela é branca, né? Então a família teve aquele, tipo um racismo. Até a menina nascer. Quando ela nasceu, a gente achava que ela fosse ser negra, mas ela acabou ficando mulata. Daí todo mundo acabou se apaixonando.

De início, ela nega que há na família uma questão relacionada à cor/raça. Depois, afirma que o fato do primeiro marido de Maria ser o que ela nomeia como "negro, negro" gerou uma preocupação sobre a cor com que Joana iria nascer. Em seguida, ela nos faz entender que o fato de Joana não ter nascido negra é o que permitiu a todos se apaixonarem. Há diferentes questões neste fragmento. Talvez a mais relevante seja a de que é necessário cegar a cor para se apaixonar. Chega a ser perturbador ouvir Valéria dizer que Joana não nasceu negra e que por isto todos se apaixonaram. Podemos concordar com Elizabeth Hordge-Freeman (2015), quando ela afirma que a tonalidade da cor e os traços físicos, a saber, a interpretação sobre o fenótipo de cada membro das famílias negras, podem estar ambos intrinsecamente ligados a distribuições de afetos que privilegiam aqueles com maior proximidade à estética da branquitude, em detrimento daqueles interpretados com características mais de negros. Ou seja, "as hierarquias raciais dão forma às famílias afro-brasileiras e, ao mesmo tempo, tornam visíveis as consequências afetivas de práticas que naturalizam a inferioridade negra" (HORDGE-FREEMAN, 2015, p. 71). O fato de a família nomear Joana como "mulata" nos pareceu uma condição para que as pessoas da família se sentissem autorizadas a se apaixonar por ela. O que se nega, portanto, não é a cor real do outro, mas sim todo o significado racista de nossa sociedade, que recairá sobre o outro quando "chegar a hora" de ele se entender como negro. É aí que reside o paradoxo da negação, pois o que parece uma solução contra o racismo acaba por reafirmá-lo e reforçá-lo. Para ficar longe do significado racista sobre "ser negro", estes sujeitos negam a negritude e perdem a possibilidade de desconstruir os estereótipos negativos atrelados ao signo 'negro'. Veremos, a seguir, como este discurso fez efeito na forma como a própria Joana se autoclassifica:

Pesquisadores: E você, Joana, como você se autoclassifica?

Joana: Como meio termo, morena. Eu sei que, às vezes, tenho o meu lado branco, mas eu gosto da minha cor escura. 
Pesquisadora: O que é lado branco?

Joana: Assim... As pessoas negras têm aquele cabelo, assim, mais cacheado, gostam de samba [...] eu já não sou muito assim. Gosto de cabelo liso, muito liso, que é mais bonito, e não gosto muito de sambar, não.

Joana, diferentemente de Valéria, não nega sua cor, mas age de forma a tentar desvalorizar ou "apagar" qualquer traço em que o contorno da pele que ela nomeia como escura seja preenchido com identificações culturais que ela caracteriza como "negras". Deste modo, ao alisar o cabelo e dizer que não gosta de samba, Joana faz um movimento de aproximação do que ela caracteriza como "lado branco". Aqui, cabe a pergunta: o que Joana quis dizer com "lado branco"? A branquitude, sabemos, é produto da história e é uma categoria relacional. Como outras, não tem significado intrínseco, mas apenas significados socialmente construídos. O que Joana fez foi legitimar os significados positivos ligados ao branco e os negativos ligados ao negro, reafirmando que cabelo liso é branco, e que cabelo liso é mais bonito.

\section{CONSIDERAÇÕES FINAIS}

Nas falas de Joana e de Juliana percebe-se como a representação negativa ou a negação do negro se assemelham ao trabalho etnográfico da antropóloga norte americana France Winddance Twine (1998). Twine aponta formas e discursos que estabelecem a manutenção do racismo e também a negação do negro e da história negra no interior destas relações. Para ela, existem, nos discursos oficiais dos brasileiros, conteúdos que evidenciam este comportamento de negação da herança negra, justamente nas pessoas negras em relacionamento com pessoas brancas. São eles: a) a ideia de que a discriminação acontece única e exclusivamente por conta da distribuição desigual de renda na sociedade; b) o discurso romântico da identidade nacional do brasileiro, fruto da miscigenação entre brancos, negros e indígenas; c) a ideia de categorização demográfica e hierarquização das pessoas brancas como melhores que as pessoas negras; d) a ideologia de inferiorização da cultura Africana em detrimento da europeia e; e) o afastamento do racismo, a partir do discurso de que no passado ou em outros lugares há racismo, mas não no presente.

Conforme dito no início deste artigo, os depoimentos acima apresentam parte dos dados de uma pesquisa mais ampla, que avançou também em configurações raciais diferentes e múltiplas. Aqueles que foram elencados 
aqui, foram-no para ilustrar como funciona esse sofisticado mecanismo de negação que nos parece ser um dos efeitos psicossociais mais importantes do racismo apresentado no interior das famílias inter-raciais. O que a fala de Estela e Valéria nos indica é que elas demonstram entender o racismo não como uma ideologia que afeta todos os âmbitos do cotidiano, mas sim como algo abstrato ou mesmo um movimento radical de interdição tal como apontou a pesquisa de Twine (1998). Ou seja, não gostar das tranças, do nariz, do cacheado do cabelo, da cultura, é visto como mera questão de "opinião" e não como uma ideologia racista. É possível afirmar, portanto, que na sociedade brasileira, neste momento histórico presente, há certas condições conjunturais bastante complexas que permitem aos sujeitos um comportamento ideológico e discursivo singular e contraditório. Eles podem, de maneira simultânea e coordenada: a) ser contra o racismo, b) achar que o racismo é um mal que todos devem combater, c) sagrar casamentos inter-raciais e d) ser racistas.

É ainda importante apontar que estas entrevistas foram feitas em um momento em que, através da atuação dos movimentos negros, os discursos sobre raça e racismo dentro do ambiente universitário e das redes sociais são construídos para positivar as identidades negras e elevar a autoestima desta população. Este aspecto é muito diferente de um passado muito próximo, no qual as mães entrevistadas estavam inseridas. Portanto, ainda que seja evidente o racismo implícito em suas falas, elas vivenciaram experiências de um passado em que, talvez, a única opção fosse a de buscar mecanismos de proteção tais como o de negação. Já seus filhos fazem parte de outra geração que, dentre negros e brancos, teve acesso a um debate sofisticado sobre raça, do qual essas mães estão tendo contato através de seus filhos só agora. Neste sentido, pode-se pensar e vislumbrar que considerar o filho como "quase" branco era algo "positivo" para uma geração que se apropriou irrefletidamente da ideologia do embranquecimento, assim pode ser difícil para estas mães, compreenderem esta nova realidade construída por meio da positivação dos signos relacionados a "ser" negro no Brasil.

Ainda sobre as mães apresentadas neste artigo, ressaltamos a importância de afirmar que nós não pensamos que os comportamentos apontados são análogos ou exclusivos à função materna da família inter-racial, mas em ambos os casos, os pais estavam ausentes e, portanto, apenas as respostas maternas foram analisadas. Com isto, reiteramos: no Brasil, esta configuração de pai ausentes, pais que abandonam etc., é bastante comum, devido a uma estrutura desigual entre homens e mulheres que, no âmbito do seio familiar, se desdobra da maneira explicitada.

Por fim, vislumbramos que, apesar deste artigo apontar para as opressões vividas no seio familiar, nossa pesquisa contribui no sentido de 
compreendermos as famílias inter-raciais, sobretudo, por uma ótica que vise não apenas apontar a opressão causada pelo discurso racista, mas também, se projetar para uma possível solidariedade genuína entre as redes familiares que possam possibilitar esses filhos orientem outras gerações; não apenas as futuras, mas também a de seus pais.

\section{REFERÊNCIAS}

BARROS, Z. S. Casais inter-raciais e suas representações acerca de raça. 199 f. 2003. Dissertação (Mestrado em Ciências Sociais - Antropologia) - Universidade Federal da Bahia, Faculdade de Filosofia e Ciências Humanas, Programa de PósGraduação em Ciências Sociais. Salvador, 2003.

BENTO, M. A. Branqueamento e branquitude no Brasil. In: BENTO, M. A., CARONE, I. (Orgs.). Psicologia social do racismo. 3. ed. Petrópolis: Vozes; 2007. p. 25-55.

CARONE, I. Breve histórico de uma pesquisa psicossocial sobre a questão racial brasileira. In: BENTO, M. A., CARONE, I. (Orgs.). Psicologia social do racismo. 3. ed. Petrópolis: Vozes, 2007. p. 13-24.

COSTA, J. F. Da cor ao corpo: a violência do racismo. In: SOUZA, N. Tornar-se negro: as vicissitudes da identidade do negro brasileiro em ascensão social. Rio de Janeiro: Graal; 1983.

D’ADESKY, J. Pluralismo étnico e multiculturalismo: racismos e anti-racismos no Brasil. Rio de Janeiro: Pallas, 2001.

FREUD, S. A negativa (1925). In: . O Ego e o Id e outros trabalhos (1923-1925). Rio de Janeiro: Imago, 1976. (Edição Standard Brasileira das Obras Psicológicas Completas, Vol. $19)$.

GUIMARÃES, A. S. A. Racismo e anti-racismo no Brasil. Rio de Janeiro: Ed. 34; 1999.

GUIMARAES, Antonio Sérgio Alfredo. Como trabalhar com "raça" em sociologia. Educ. Pesqui., São Paulo, v. 29, n. 1, p. 93-107, June 2003.

HASENBALG, C. Discriminação e desigualdades raciais no Brasil. Rio de Janeiro: Graal; 1979.

HORDGE-FREEMAN, E. The color of love: racial features, stigma, and socialization in black Brazilian families. Texas: University of Texas Press, 2015.

IBGE - INSTITUTO BRASILEIRO DE GEOGRAFIA E ESTATÍSTICA. CENSO DEMOGRÁFICO. Censos demográficos 1991. Rio de Janeiro: 1991. Disponível em: <http:// www.ibge.gov.br/home/estatistica/populacao/censodem/default_censo1991.shtm>. Acesso em: 29 maio 2015.

MANDELBAUM, B. Psicanálise da família. São Paulo: Casa do Psicólogo: 2008.

MOUTINHO, L. Razão, cor e desejo. São Paulo: UNESP, 2004. 
PETRUCCELLI, José Luís; SABOIA, Ana Lucia (Orgd.). Características étnico-raciais da população: classificações e identidades. Rio de Janeiro: IBGE, 2013. (Estudos e análises: informação demográfica e socioeconômica 2). Disponível em: <https://biblioteca.ibge.gov.br/ visualizacao/livros/liv63405.pdf>. Acesso em 30 maio 2015.

SANSONE, L. Pai Preto, Filho Negro. Trabalho, cor e diferença de geração. Estudos AfroAsiáticos, n. 25, p. 73-98, 1993.

SCHUCMAN, L. V. Entre o "encardido", o "branco" e o "branquíssimo": raça, hierarquia e poder na construção da branquitude paulistana. 122f. 2012. Tese (Doutorado em Psicologia) - Instituto de Psicologia, Universidade de São Paulo, São Paulo, 2012.

TWINE, F. W Racism in a Racial Democracy. New Jersey: Rutgers University Press. 1998.

Agência de fomento: Fundação de Amparo à Pesquisa do Estado de São Paulo [FAPESP]. Processo: 12/24518-6. Bolsas no Brasil - Pós-Doutorado. 01 de junho de 2013 - 30 de setembro de 2016. Pesquisador responsável: Belinda Piltcher Haber Mandelbaum. Beneficiário: Lia Vainer Schucman.

Submissão em: 15/06/2017

Revisão em: 02/08/2017

Aceite em: 09/08/2017

Lia Vainer Schucman possui graduação em Psicologia pela Universidade Federal de Santa Catarina (2003), mestrado em Psicologia pela Universidade Federal de Santa Catarina (2006) e doutorado em Psicologia Social pela Universidade de São

Paulo (2012). Tem experiência na área de Psicologia, com ênfase em movimentos sociais, atuando principalmente nos seguintes temas: psicologia social, movimentos sociais, racismo, educação intercultural e identidade.

liavainers@gmail.com

Belinda Piltcher Haber Mandelbaum é Professora Associada do Departamento de Psicologia Social e do Trabalho, onde coordena o Laboratório de Estudos da Familia (LEFAM). belmande@usp.br

Felipe Luis Fachim é doutorando pelo programa de Educação: Psicologia da Educação da Pontifícia Universidade Católica de São Paulo, mesmo programa em que obteve o título de mestre (2017). fefachim@gmail.com 